\title{
Women Role in Agricultural Value Chain:Review in Ethiopia
}

\author{
Metages Belete \\ Wolaita Sodo University College of Agriculture Department of Agribusiness and value chain management, PO \\ Box: 138, Wolaita Sodo University, Ethiopia
}

\begin{abstract}
Ethiopia is a country where more than $85 \%$ of its population depend on rain fed agriculture. Agriculture is the back bone of the national economy. Both men and women have been playing a significant role in the development of agricultural production. This paper draws on the available empirical evidence to review in which areas and to what degree women participate along agricultural value chain. Women make essential contributions to the agricultural and rural economies in all developing countries. Their roles vary considerably between and within regions. Their activities typically include producing agricultural crops, processing and marketing. Rural women often manage complex households and pursue multiple livelihood strategies. Their activities typically include producing agricultural crops, tending animals, processing and preparing food, working for wages in agricultural or other rural enterprises, collecting fuel and water, engaging in trade and marketing, caring for family members and maintaining their homes. However, evidence suggests that women tend to lose income and control as a product moves from the farm to the market. Women participation influenced by social, cultural, demographic, institutional and economic factors. So, it needs both governmental and non-governmental organizations intervention to support, encourage and give priority for increasing production, processing and marketing of agricultural products and minimize differences among women and men.
\end{abstract}

Keywords: women, women role and agricultural value chain

DOI: $10.7176 / \mathrm{JCSD} / 45-03$

\section{Introduction}

\subsection{Background}

Development policies and programmes in most developing countries continue to contain assumptions regarding gender roles that place women in stereotyped work such as housewives and secretaries (Bhatta 2001). In order to enable women to actively participate in the sustainable development process of Ethiopia and the other developing countries, there is a great need to promote changes in policies, laws, structures and attitudes and development programmes.

Women make essential contributions to the agricultural and rural economies in all developing countries. Their roles vary considerably between and within regions and are changing rapidly in many parts of the world, where economic and social forces are transforming the agricultural sector. Rural women often manage complex households and pursue multiple livelihood strategies. Their activities typically include producing agricultural crops, tending animals, processing and preparing food, working for wages in agricultural or other rural enterprises, collecting fuel and water, engaging in trade and marketing, caring for family members and maintaining their homes. Many of these activities are not defined as "economically active employment" in national accounts but they are essential to the wellbeing of rural households. (Frank, 1999), women constitute the backbone of food production system in the economy of Ethiopia (EARO, 2000).

\subsection{Objectives}

$\checkmark$ To understand the role of women along the value chain

$\checkmark \quad$ To identify determinant factors affecting women participation along the value chain

\section{Discussion}

\subsection{Gender role in Ethiopia}

Since 1993, the government of Ethiopia committed itself to promoting gender empowerment through the implementation of the Beijing platform of action. Institutional mechanisms for advancing the course of women involves capacity-building financed by a proper institutional development fund; paying special attention to women fuel wood needs; increasing the access of women/girls to education; improving participation in decision making and in local and national elections; and other measures taken by the government of Ethiopia to improve the employment situation of women are indicative of the country's commitment to improving gender roles in national development (United Nations 2002).

Ethiopia is a country where more than $85 \%$ of its population depend on rain fed agriculture. Agriculture is the back bone of the national economy. Both men and women have been playing a significant role in the development of agricultural production. The role and the contribution of both male and female, in the agricultural activities, is not necessarily the same in all parts of the country. Since Ethiopia is the country of 
multi-ethnic and multi-cultural groups, all ethnic and cultural groups have different gender roles in agriculture. Gender division of labor in rural Ethiopia varies in terms of farming systems, cultural settings, location and the different wealth categories (Abera et al. 2006; Mollel and Mtenga 2000). Gender roles in the country also vary according to ethnicity, income, and status.

According to Frank (1999) women do almost half of the labor required for agricultural production in Ethiopia. In Ethiopia, in spite of some variations, it is common to see women assist their husbands in various agricultural activities as soil preparation, manuring, weeding and harvesting. When men spend their time in the farm, women engage on the breeding of livestock. According to Hanna (1990), women in Ethiopia participate in all aspects of agricultural production except ploughing. Despite their active role in agricultural production, they get little value due to their lower position in the society. Hence, it is the men that the society considers as producers.

\section{Role of women along the value chain}

\subsection{Women role in agricultural production}

Agricultural sector is the principal engine of growth of the Ethiopian economy; it employs $83 \%$ of the labour force, contributes about $90 \%$ of exports and $45 \%$ of gross domestic product (GDP), and provides about $70 \%$ of the country's raw material requirement for large-and medium-scale industries (MoARD, 2009). Women across the developing world are disadvantaged relative to men. Under male-dominated social structure and political system, women are denied equal access to land structure and extension services (Okafor et al., 2002).

According to Nahusenay (2017) rural women work much longer hour than men. Women spend more time in seed bed preparation, harvesting of crops, weeding, transporting, storage preparation, etc. These activities may be done either individually or through group works (wonfel and debbo). G. S. Ogato1 et al., (2009) reported that during the agriculture peak seasons, women work more than double the hours done by men. The task of fetching water and collecting fuel wood is the sole duty of women, assisted most of the time by girls. Females' contribution to crop production and management is significantly higher than that of males because they participate in almost all farming activities, domestic tasks and community development work. Helen (1992) indicated that the women of the Awra Amba community equally participate with men in agricultural production. The women plough the land with oxen while men perform domestic activities at home. The significant contribution of females in reproductive and productive works and community development should serve as a good guide for rural development interventionists. A clear implication of females' double workload in rural communities of Ethiopia is that policymakers, planners and development agents must have a holistic understanding of the relative and often shifting roles of men and women in agriculture, natural resource management, decision-making, use of traditional knowledge and practices, division of labour between women and men (Upadhyay 2005).

According to Zemeda (2015) women's are confined at lower level dairy value chain activity which is routine and daily and needs more time and in considerable activities i.e. cleaning dairy shade, watering dairy cow, caring dairy cow and calves, milking, milk container cleaning, milk quality control. Women play a significant and crucial role in production of various horticultural crops. The participation of women was more in various production and post production activities of vegetables than fruits and flowers. Women's participation was maximum in stubble collection, seed sowing, and seed cleaning, transplanting, and weeding of horticultural crops. They play major part of field preparation, manure application, harvesting, cleaning and collection of produces, sorting and grading. Poultry production is a suitable enterprise for landless women and young people, as poultry production does not require much land and capital. The gender baseline survey undertaken by IPMS revealed that women are responsible for most of the production activities such as hatching, rearing, health, feeding, watering, protection and egg collection (Aregu et al. 2011).

\subsection{Women role in agricultural products processing}

In most rural communities in Ethiopia, women work from dawn to dusk and, in contrast with men, have little time for leisure or socializing. The overall length of the working day for women does not vary much between the wet and dry seasons. They work for between 10-12 hours per day, half of which is spent on household tasks such as fetching water and firewood, preparing and cooking food, and caring for children. Women from rich and middle wealth households often trade in agricultural products, whereas poorer women work as casual labourers on farms and in the homes of richer households; they also harvest natural resources for resale (fuel wood, sorghum stalks and grass) or engage in low input activities such as cotton spinning or making injera for sale (Lemlem et al., 2015).

According to Nahusenay (2017) women solely perform milk processing, barn cleaning and care of new born animals. According to Zemeda (2015) women's are confined at lower level dairy value chain activity which is routine and daily and needs more time and in considerable activities i.e. cleaning dairy shade, watering dairy cow, caring dairy cow and calves, milking, milk container cleaning, milk quality control, milk processing, butter 
selling. Woman's productivity is predominated in the processing and marketing of food in rearing, and food processing and industries (The Ethiopian Herald, 2004). Enset processing is done by women and is currently labor intensive, dangerous and time consuming (CIDA, 2013). According to Mohammed (2014) Women have dual responsibility for farm and household production. Women participation is significant in postharvest activities such as threshing, winnowing, drying, grinding, husking, storage. According to the Food and Agriculture Organization (2001), the many activities required to process foodstuffs into edible or marketable form are traditionally women's responsibilities and almost entirely undertaken by female members of the household.

\subsection{Women role in agricultural products marketing}

Small-scale rural producers - both men and women - face a number of constraints in accessing markets, such as lack of access to productive assets (e.g. land, water, and finance), education, technical skills and new technologies; high transport and transaction costs; and lack of bargaining power. However, women farmers face greater disadvantages than their male counterparts. They face social, economic and political constraints ranging from social norms and customs that dictate the type of work they can do and the conditions in which this work must take place, to gender-unequal laws which limit or constrain their access to productive assets such as land, livestock, productive inputs and finance (FAO, IFAD, ILO, 2010). In addition, women often have less access to education, knowledge, information and technologies than men. Finally, women's access to markets can be limited by a lack of social services such as child care.

According to Messay (2012) the level of household participation in marketing varied from one type of agricultural product to the other. Women participation in vegetable and fruit, animal products (such as milk, cheese and butter), chickens and egg marketing is significantly higher than men. Women are expected to run the household with the money they were provided by their spouses, and therefore they struggle to manage their income in accordance with the basic family needs.

Women sometimes sell small quantities of crop in secret which results market inefficiencies and they have little control over the income when the volume of the produce per household is more substantial because of the dominance of men in the marketing (Lemlem et al., 2015). However fruit and vegetable production is generally women's business starting from planting to harvesting, selling and preparing food for household consumption (Mulunesh et al., 2016). According to FAO (1997) in Ethiopia women are commonly responsible, along with their children, for taking care of small livestock, production and marketing of butter, cheese, and vegetables. They also engage in non-farm income activities such as petty trading, beer brewing and leather work.

\section{Factors affecting women participation along the value chain}

According to Gurung (2006) in East Africa Women increasingly supply national and international markets with traditional and high-value produce, but com-pared to men, women farmers and entrepreneurs face a number of disadvantages, including lower mobility, less access to training, less access to market information, and less access to productive resources. Evidence suggests that women tend to lose income and control as a product moves from the farm to the market.

In Halaba southern part of Ethiopia the contributing factors that influences women's role in agriculture depends upon the women's dependence on their husband, illiteracy, ignorance, low social status and traditional religious and cultural dominance, political and economic status (Messay 2012). According to Yaekob (2010) childbearing and rearing can have different effects on labour force participation it prevents women from working; it can affect the quality and quantity of women's work and it can influence the type of work performed by women. Regarding fruit and vegetable production women faced many challenges such as lack of gendersensitive approaches in extension (i.e. male dominated agriculture services), low capacities of women for vegetable cultivation due to limited knowledge and skills, lack of access to inputs (i.e. seeds, pesticides), innovations and technologies (e.g. preserving and processing systems), consistent markets, value chains and stable prices and damage by wildlife in home gardens (Mulunesh et al., 2016). Additionally women faced many challenges in crop production and management such as land shortage and high price of agricultural inputs, less access to credit than men and can only get credit if they are household heads, lack of access to extension services (G. S. Ogato1 et al., 2009).

According to Almaz et al. (2014), low market linkage, less farming experience, low market price, low production and productivity are the constraints for female headed households along vegetable value chain.

\section{Conclusion and recommendation}

Agricultural sector is the principal engine of growth of the Ethiopian economy; it employs $83 \%$ of the labour force, contributes about $90 \%$ of exports and $45 \%$ of gross domestic product (GDP), and provides about $70 \%$ of the country's raw material requirement for large-and medium-scale industries. Women have a significant participation along agriculture value chain activities such as production, processing and marketing of agricultural 
products. Their participation is different from one community to another community. However, their participation influenced by social, cultural, demographic, institutional and economic factors. The major factors include most of the women are illiterate; they spent more time on reproductive works which affect their role in productive activities; women have less access of extension and credit services; low marketing linkage along the value chain.

In order to improve women participation and benefit from the agricultural value chain activities both governmental and non-governmental respective bodies should divert their efforts toward improving women status in the society and living condition through economic benefit. With the current situation of women, there should be gender focused interventions that support, encourage and give priority for increasing production, processing and marketing of agricultural products and minimize differences among women and men.

\section{Reference}

Abera G, Gudeta H, Belissa M, Shale G, Degefe A, Akassa B (2006). Gender Based Roles and Resource Use Right in Potato Production and Marketing System: The Case of Some Districts in Oromia, Ethiopia. A Research Report. Addis Ababa: OARI and OSSREA.

Almaz G, Dr Workneh N, Dr Edilegnaw W, Dr Gezahegn A. (2014). Constraints of vegetables value chain in ethiopia: a gender perspective

Bhatta G, (2001). Of Geese and Gander: Mainstreaming Gender in the Context of Sustainable Human Development. Journal of Gender Studies, 10(1): 17-32.

EARO, (2000). Institutionalizing gender planning in agricultural technology generation and transfer processes: proceeding of the national workshop from 25- 27 Oct 1999, EARO, Addis Ababa.

FAO. 2010. National Gender Profile of Agricultural Households. Report based on the Lao Expenditure and Consumption Surveys, National Agricultural Census and the National Population Census. Food and Agriculture Organization of the United Nations, Rome and Ministry of Agriculture and Forestry, Vientiane.

Food and Agriculture Organization (FAO). 2001. Enhancing Production capacities: The Agricultural Sector and Food Security.The Role of Agriculture in the Development of LDCs and their Integration into the World Economy.The United Nations Conference on the Least Developed Countries. Brussels. Rome. 14 -20 May, 2001.

Frank, E. (1999) Gender, Agricultural Development and Food Security in Amhara, Ethiopia: The Contested Identity of Women Farmers in Ethiopia, USAID/EthiopiaHelen, P (1992) Gender, Development and Identity: An Ethiopian Study, London, Zed Books.

G. S. Ogato, E. K. Boon, J. Subramani (2009). Gender Roles in Crop Production and Management Practices: A Case Study of Three Rural Communities in Ambo District, Ethiopia

Hanna, K. (1990), Gender Relations in Mobilizing Human Resources' in S. Pausewang et.al, Ethiopia: Rural Development Options, Londn, Zed Books.

Lemlem A, Ranjitha P, Clare B. S (2015). The role of gender in crop value chain in Ethiopia

Messay T. (2012). An assessment on the role of women in agriculture in southern nation nationality people's region: the case of Halaba special woreda, Ethiopia

Mollel NM, Mtenga NA (2000). Gender Roles in the Household and Farming Systems of Techenzema, Morogoro-Tanzania. South African Journal of Agricultural Extension, 29: 73-88.

Mulunesh A, Sarah N, Beneberu A, Tina B (2016). Being a woman farmer is like being cursed: Gender challenges in horticultural research in South Western Ethiopia.

United Nations, (2002). Johannesburg Summit 2002: Ethiopia-country Profile. From <http: //www.un.org/ esa/agenda21/natlinfo/wssd/ethiopia.pdf $>$.

Zemeda G. (2015). The role of gender in dairy value chain: the case of central zone of Tigray.

Yaekob Mentena (2010), "The Role of Women in Agriculture: A Case Study of Arba Minch Zuria woreda, Semen Omo Zone.” (MA Unpublished Thesis). A.A.U.: Addis Ababa. 